\title{
Exploring the Active Compounds of Traditional Mongolian Medicine Agsirga in Intervention of Novel Coronavirus (2019-nCoV) \\ Based on HPLC-Q-Exactive-MS/MS and Molecular Docking Method
}

\author{
Jie Cheng ${ }^{1, \#}$, Yuchen Tang, ${ }^{1, \#}$, Baoquan Bao ${ }^{1, *}$, Ping Zhang, ${ }^{1, *}$
}

\author{
${ }^{1}$ College of Pharmacy, Inner Mongolia Medical University, 010110, Hohhot, China \\ *Correspondence to: baobaoquan123@yeah.net (Baoquan Bao) ; pingzhang@vip.126.com(Ping Zhang) \\ \# These authors contributed equally to this work
}

Objective: To screen all compounds of Agsirga based on the HPLC-Q-Exactive highresolution mass spectrometry and find potential inhibitors that can respond to $2019-\mathrm{nCoV}$ from active compounds of Agsirga by molecular docking technology.

Methods: HPLC-Q-Exactive high-resolution mass spectrometry was adopted to identify the complex components of Mongolian medicine Agsirga, and separated by the high-resolution mass spectrometry Q-Exactive detector. Then the Orbitrap detector was used in tandem high-resolution mass spectrometry, and the related molecular and structural formula were found by using the chemsipider database and related literature, combined with precise molecular formulas (errors $\leq 5$ $\times 10^{-6}$ ), retention time, primary mass spectra, and secondary mass spectra information, The fragmentation regularities of mass spectra of these compounds were deduced. Taking ACE2 as the receptor and deduced compounds as the ligand, all of them were pretreated by discover studio, autodock and Chem3D. The molecular docking between the active ingredients and the target protein was studied by using AutoDock molecular docking software. The interaction between ligand and receptor is applied to provide a choice for screening anti-2019-nCoV drugs.

Result: Based on the fragmentation patterns of the reference compounds and consulting literature, a total of 96 major alkaloids and stilbenes were screened and identified in Agsirga by the HPLC-Q-Exactive-MS/MS method. Combining with molecular docking, a conclusion was got that there are potential active substances in Mongolian medicine Agsirga which can block the binding of ACE2 and 2019-nCoV at the molecular level.

Key words: Agsirga; 2019-nCoV; ACE2; molecular docking; HPLC- MS 


\section{Introduction:}

The 2019 novel coronavirus (2019-nCoV) caused the pneumonia outbreak in Wuhan, hubei, China, in late December 2019 and has rapidly spread to more than 20 countries and regionsaround the world. The World Health Organization (WHO) has declared the 2019- nCoV epidemic a public health emergency of international concern (PHEIC). By Mar 2, 2020, more than 80174 individuals were infected and more than 2900 fatalities had been reported in China. For now, it is mainly to use the combination of traditional Chinese and Western medicine to treat In clinical ${ }^{[1]}$, but there is no specific antiviral drugs for this new epidemic. Therefore, it is urgent and significant to study new effective therapeutic methods and drugs.

Mongolian medicine is an important part of traditional Chinese medicine. In the past millennium, Mongolian medicine has played a unique role in the prevention and treatment of epidemic and it has very good clinical effect in curing and preventing infectious diseases such as influenza, tuberculosis, SARS,H7N9 and H1N1. According to Mongolian medicine, the outbreak infectious diseases are called pestilence and the treatment of pestilence is an important part of Mongolian medicine.The 2019-nCoV pneumonia belongs to the category of"epidemic fever" and "sticky epidemic" in Mongolian medicine, it is a pestilence fever caused by virus infection ${ }^{[2]}$. Therefore, in the development stage of specific western medicine, the combination of Mongolian, Chinese and Western medicine may be a breakthrough.

Agsirga, the dried roots and rhizomes of Veratrum nigrum L., is a traditional Mongolian medicine commonly used to treat tumor and cancer in the characteristic "Purgative therapy" of Mongolian medicine ${ }^{[3]}$, and its clinical effect is obvious. There is no report on the treatment of pestilence fever caused by virus infection, but the main components of Agsirga, For instance, resveratrol, cyclophosphamide, sinafenamine, etc, have excellent curative effect on virus infection, such as DNA viruses: Herpesvirus ${ }^{[4-6]}, \mathrm{HBV}^{[7,8]}$ and RNA viruses: Enteroviruses (EV11, EV71, EV84, CVB3 and CVA10 $)^{[9,10]}, \mathrm{HIV}^{[11,12]}, \mathrm{HCV}^{[13,14]}$, DFV, influenza virus, Respiratory syncytial virus $^{[15]}$. There are many chemical components with complex structure and huge polar differences in Mongolian medicine Aghiriga, the traditional method of liquid phase analysis can not identify all kinds of them. We intends to screen all compounds of Agsirga with the effection of anti-2019-nCoV based on the HPLC-Q-Exactive high-resolution mass spectrometry and molecular docking 
technology.

Molecular docking is a a mature technology for the direct design of chemicals by using computational tool, which is widely used for the study of protein-ligand interactions and for drug discovery and development. Its principle is to simulate the geometric structure and intermolecular force of molecules by means of chemometrics, and to find the low-energy binding mode of active sites between small molecules (or ligands) and protein with known structures. Docking is then used to calculate and predict the bound conformation and binding free energy of small molecules to the target protein, to identify new inhibitors in the target prediction of drug organisms for drug development. In this study, molecular docking screening was carried out to evaluate the binding energy between the key compounds of Agsirga and the angiotensin-converting enzyme 2(ACE2) which is one of target protein in the process of 2019-nCoV infection, and obtain active compounds for the further development of anti-2019nCoV drugs.

\section{Experimental}

\subsection{Chemicals and reagents}

HPLC-grade acetonitrile was purchased from Fisher (USA). Formic acid was purchased from Tianjin Yongsheng Fine Chemical (Tianjin, China). Deionized water $(18 \mathrm{M} \Omega / \mathrm{cm})$ was purified by a water purification system from Millipore (Bedford, MA, USA).

Reference substances of(1) jervine, (2) verdine, (3) pseudojervine, (4) veratramine, (5)

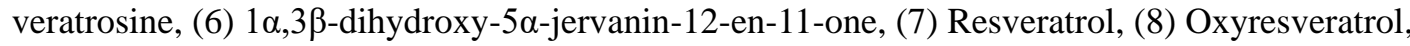
(9) piceid, (10)Peimine, (11) Peiminine, (12) imperialine, (13) 2 , 3, 5, 4' - tetrahydroxysilbene- 2O- $\beta$ - D- glucopyranoside, (14) Isoscopoletin, (15) methyljervine- N- 3'- propanoate, (16) resveratrol- 4,3' - di- O- $\beta$ - D- glucopyranoside, (17) L- Pyroglutamic acid methyl ester, (18) desoxyrhaponticin, (19) $\alpha$ - D- Glucopyranoside, 2 - methoxy- 4- methylphenyl, (20) $\beta$ - DGlucopyranoside, 2- methoxy- 4- (2- propen- 1-yl) phenyl 6- O- $\beta$ - D- glucopyranosyl, (21) $\beta$ - DGlucopyranoside, 2, 6 - dimethoxy-4-(2-propen-1-yl)phenyl-6-O-b-D-glucopyranosyl, (22) mulberroside A, (23) Mulberroside E, (24) Piceatannol 4'- O- $\beta$ - D- glucopyranoside were isolated from "Agsirga" species in our laboratory .and their identities were confirmed by IR, 1H- and 13CNMR, MS analyses. The purity of these substances was determined to be more than $98 \%$ by normalization of the peak areas detected by HPLC with ESI/MS. Stock standard solutions of 26 reference substances were prepared in methanol at a final concentration of $0.1 \mathrm{mg} / \mathrm{ml}$. These 
solutions were stored at $4{ }^{\circ} \mathrm{C}$ for further study.

\subsection{Sample preparation}

Herbal materials of "Agsirga" were Collected from saihanwula national nature reserve (Inner Mongolia, China), and identified by Professor Baoquan Bao (Inner Mongolia Medical University). The voucher specimens were deposited at the Herbarium of Inner Mongolia Medical University, Hohhot, China.

steroidal alkaloids: The dried roots of "Agsirga" species were powdered to a homogeneous size, and sieved through a 32 mesh screens, followed by drying at $60{ }^{\circ} \mathrm{C}$ in the oven for $2 \mathrm{~h} .1 .0 \mathrm{~g}$ of the powder of "Agsirga" were accurately weighed and pre-alkalized with $2 \mathrm{ml}$ ammonia solution (25\%) for $1 \mathrm{~h}$, and immersed in $40 \mathrm{ml}$ trichlormethane:methanol(4:1, v/v) mixture overnight, then refluxing for $2 \mathrm{~h}$. After being filtered, the extracts $(10 \mathrm{ml})$ were concentrated to dryness in vacuum at $50{ }^{\circ} \mathrm{C}$. The residue was made up to exactly $2 \mathrm{ml}$ with initial mobile phase using a volumetric flask. The resultant solutions were centrifuged at 12,000rpm for $10 \mathrm{~min}$; the supernatants were transferred to an autosampler vial for HPLC-Q-Exactive-MS/MS analysis.

Stilbene samples: $1.0 \mathrm{~g}$ of the powder of "Agsirga" (over 32 mesh screens) were accurately weighed and extracted by refluxing with $25 \mathrm{~mL}$ of $50 \%$ methanol for $1 \mathrm{~h}$. After being filtered, the extracts $(10 \mathrm{ml})$ were concentrated to dryness in vacuum at $50{ }^{\circ} \mathrm{C}$. The residue was made up to exactly $2 \mathrm{ml}$ with initial mobile phase using a volumetric flask. The resultant solutions were centrifuged at 12,000 rpm for $10 \mathrm{~min}$; the supernatants were transferred to an autosampler vial for HPLC-Q-Exactive-MS/MS analysis.

\subsection{Instrumentation and analytical conditions}

For separation, we using a Thermo ScientificTM Q ExactiveTM Quadrupole-Orbitrap Mass Spectrometer system ( Thermo Fisher Scientific, Grand Island, NY, USA) and Thermo Scientific Dionex Ultimate 3000 HPLC system. The data were captured and analyzed by Xcalibur 3.0 software, which was designed by Thermo Fisher Scientific.

For steroidal alkaloids separation, the chromatographic analysis was performed with a HPLC Agilent Zorbax Extend-C18 $(4.6 \times 150 \mathrm{~mm}, 5 \mu \mathrm{m})$. The mobile phase consisted of water containing $0.1 \% \mathrm{v} / \mathrm{v}$ formic acid (A) and acetonitrile(B). A gradient program was used as follows: 0-20min, 7 $31 \% \mathrm{~B} ; 20-30.01 \mathrm{~min}, 31-100 \% \mathrm{~B}$. The column temperature was set as $35^{\circ} \mathrm{C}$. The flow rate was 
kept at $0.3 \mathrm{~mL} / \mathrm{min}$. Sample injection volume was turned to $1 \mu \mathrm{L}$.

For stilbene separation, the chromatographic analysis was performed with a HPLC Apollo $\mathrm{C} 18(4.6 \times 250 \mathrm{~mm}, 5 \mu \mathrm{m})$. The mobile phase consisted of water containing $0.1 \% \mathrm{v} / \mathrm{v}$ formic acid (A) and acetonitrile(B). A gradient program was used as follows: 0-5min, 5-10\% B; 5-20min, 10-15\% B; 20-40min, $15 \%-40 \%$ B ; 40-45min, $40 \%-100 \%$ B. The column temperature was set as $35^{\circ} \mathrm{C}$. The flow rate was kept at $1.0 \mathrm{~mL} / \mathrm{min}$. Sample injection volume was turned to $10 \mu \mathrm{L}$.

The conditions of the ESI source were as follows: capillary temperature and aux gas heater temperature was set as 350 and $150{ }^{\circ} \mathrm{C}$, respectively; shealth gas flow rate was turned to $40 \mathrm{~L} / \mathrm{min}$ and aux gas flow rate was $2 \mathrm{~L} / \mathrm{min}$; S-lens RF level was kept at 50; spray voltage was $3.5 \mathrm{KV}$; mass spectra were recorded across the range $\mathrm{m} / \mathrm{z} 100-1000$ with accurate mass measurement of all mass peaks. steroidal alkaloids samples were analyzed in positive mode to provide information for structural identification. stilbene samples were analyzed in negative mode to provide information for structural identification.

\section{Results and discussion}

\subsection{Identification of Chemical composition in "Agsirga" species}

In addition, the effect of adding formic acid into the mobile phase was also investigated. The retention time of alkaloids was advanced by adding formic acid and the separability and peak shape was much better; and the ionizing effect of stilbene was improved by adding formic acid. The amount of formic acid to be added was estimated and $0.1 \% \mathrm{v} / \mathrm{v}$ formic acid were selected as the desired separationand ionization.

The main components of Mongolian medicine Agsirga are alkaloids and stilbenes. Due to the great difference in polarity and the fact that alkaloids are easily soluble in organic solvents under alkaline conditions, different extraction methods are used for stilbenes and alkaloids in order to achieve the best extraction efficiency.

Based on the fragmentation patterns of the reference compounds and consulting literature, a total of 96 major alkaloids and stilbenes were screened and identified in Agsirga by the HPLC-QExactive-MS/MS method, including 31 cevanine type alkaloids, 8 jervine type alkaloids, 10 veratramine type alkaloids, 7 secosolanidine type alkaloids and 18 stilbenes. (Supporting Information Table S1 and Table S2). And the total ion chromatography of the alkaloids and stilbenes are listed in Supporting Information Figure S1 to Figure S2. The results of this study clearly demonstrated the potential of HPLC-Q-Exactive-MS/MS for the rapid and sensitive structural elucidation of the multi-groups of constituents in Agsirga. 


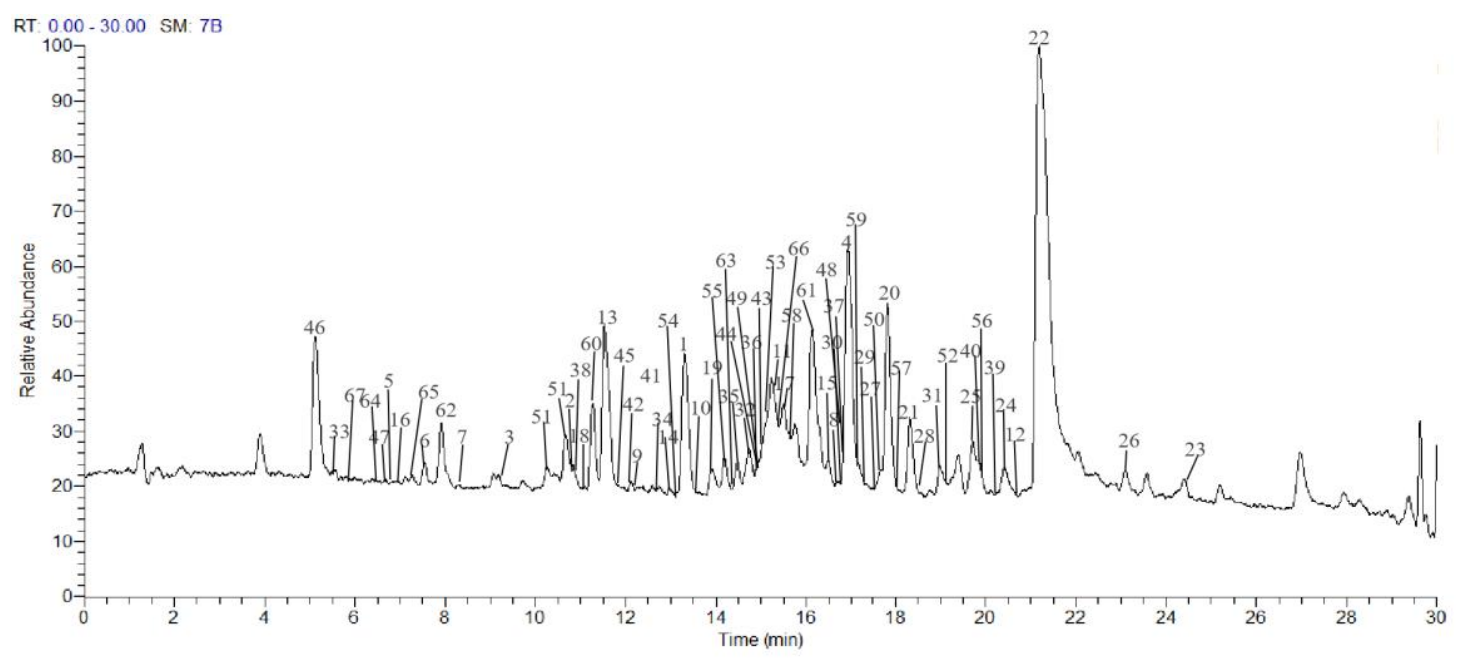

Fig. S1 total ion flow in the positive mode of Mongolian medicine Agsirga alkaloid samples

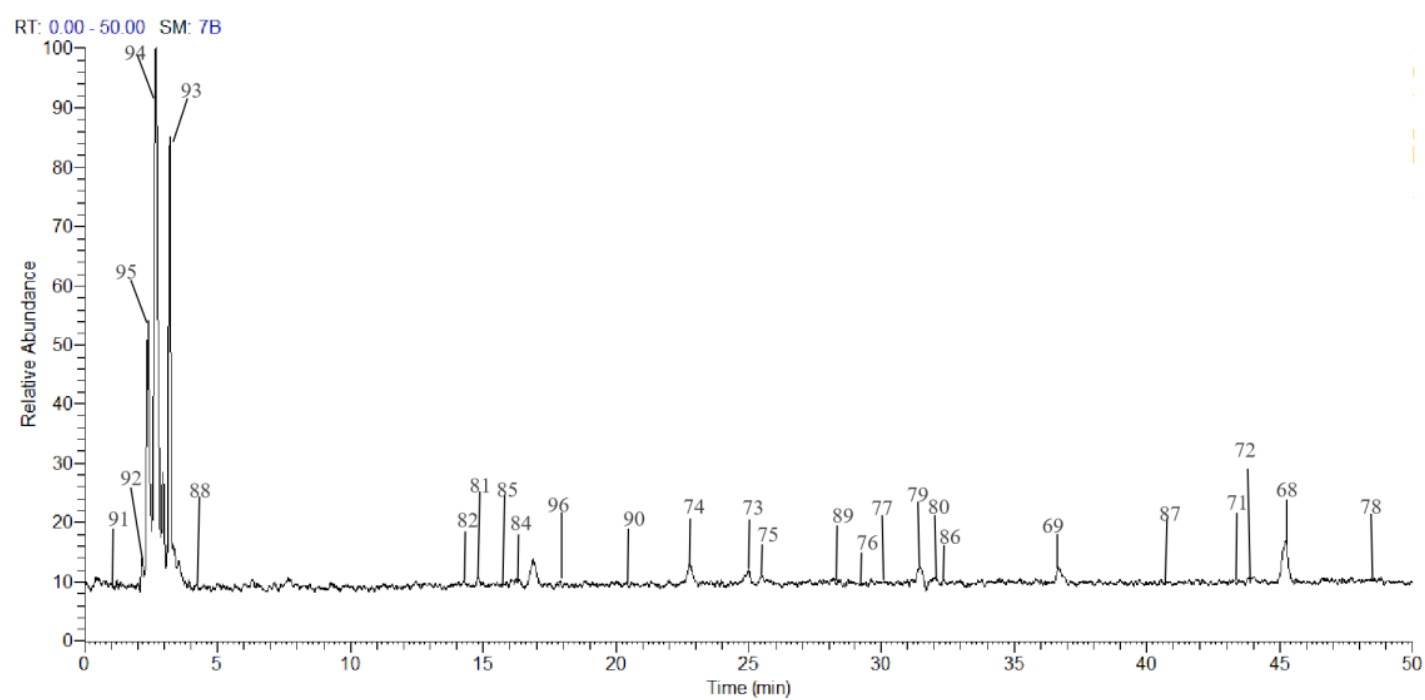

Fig. S2 total ion flow in the negative ion mode of Mongolian medicine Agsirga stilbenes samples

\subsection{Screening of potential pharmacodynamic components against 2019-ncov based on} molecular docking

In the following section, we will summarize these natural compounds in Traditional Mongolian Medicine Agsirga that may have therapeutic effects against 2019-nCov infection. To generate putative binding poses, we used the AutoDock Vina software package with the default scoring function (Trott O, Olson AJ, 2010). The structure of the full-length human ACE2 bound to the RBD of the 2019-nCoV Provided by Zhou Qiang team of West Lake University ${ }^{[19]}$. Use the discovery studio 2016 client software to remove the ligands and non protein molecules in the target protein and save them as PDB format files. Download the mol format file of the 2D structure of the 
compound from the Scifinder database (https://scifinder.cas.org), use Chem3D software to minimize its energy and convert it to PDB format for future use. We assigned the Gasteiger atomic partial charges and converted all receptors and ligands to the PDBQT format using the AutoDockTools package $^{[16]}$.

We identified the receptor binding pocket based on the structures of the full-length human ACE2 bound to the RBD of the 2019-nCoV ( Q24, D30, H34, Y41, Q42, M82, K353, R357) ${ }^{[17]}$. The calculation results show that the lowest binding free energy $(\Delta G)$ of different components combined with ACE2 is between $-2.3 \sim-7.1 \mathrm{kcal} \bullet \mathrm{mol}-1$, the median is $-6.0 \mathrm{kcal} \cdot \mathrm{mol}-1$, and $\triangle \mathrm{G}<$ $-6.0 \mathrm{kcal} \cdot \mathrm{mol}^{-1}$ as a potential anti-2019-nCoV infection active ingredient (Supporting Information Table S3 and Figure S3).

It is generally believed that the lower the energy when the conformation of ligand binding to receptor is stable, the more likely the interaction will occur. In this study, the results of molecular docking showed that the compounds with the lowest binding energy to human ACE2 were pseudojervine binding energy of $\left(-6.8 \mathrm{kcal} \bullet \mathrm{mol}^{-1}\right)$, imperialine- 3 - $\beta$ - D- glucoside binding energy of $(-7.1 \mathrm{kcal} \cdot \mathrm{mol}-1)$. According to table S3, it is not difficult to see that the potential anti-2019nCoV active components in Mongolian medicine Agsirga are mainly alkaloids, and D30 and H34 are their mainly binding sites.

As we know, The overall interface between the 2019-nCoV and ACE2 mediated mainly through polar interactions, An extended loop region of RBD spans above the arch-shaped $\alpha 1$ helix of ACE2 like a bridge. The $\alpha 2$ helix and a loop that connects the $\beta 3$ and $\beta 4$ antiparallel strands, referred to as Loop 3-4, of the PD also make limited contributions to the coordination of RBD. The contact can be divided to three clusters. The two ends of the "bridge" attach to the amino (N) and carboxyl (C) termini of the $\alpha 1$ helix as well as small areas on the $\alpha 2$ helix and Loop 3-4. The middle segment of $\alpha 1$ reinforces the interaction by engaging two polar residues. ${ }^{[19]}$

Human ACE2 is the surface receptor for SARS-CoV and 2019-nCoV to enter the host cells. It is the channel and key factor for successful infection of the virus. The University of Hong Kong ${ }^{[18]}$ has first revealed that SARS-CoV, MERS-CoV and 2019-nCoV may enhance their infection and transmission ability by inducing ACE2 receptor on host cell surface. ACE2 may be used as the cell receptor of 2019-nCoV which enter the cell through ACE2 for reproduction and further transmission. Reducing the expression of ACE2 can prevent the virus from entering the cell. According to 
previous studies, the main components of Mongolian medicine Agsirga are alkaloids and stilbene compounds, among which stilbene compounds have been found to bind well with 2019-nCoV 3CL hydrolase ${ }^{[20]}$; alkaloid compounds have antitumor and antibacterial activities ${ }^{[21]}$. Matrine sodium chloride injection has a significant therapeutic effect on the mice model with pneumonia caused by coronavirus, and the inhibition rate of lung index in the model group was $86.86 \%$ and $76.53 \%$, which was related to the inhibition of virus replication, the regulation of immune function and the inhibition of the release of inflammatory factors. We wonder whether veratrum alkaloids have the similar effects with Matrine sodium chloride injection and whether they can reduce the expression of ACE2 to block the invasion of virus into cells.

The structure of the 2019-nCoV RBD (nCoV-RBD) is similar to the RBD of SARS-CoV (SARS-RBD). Despite the overall similarity, a number of sequence variations and conformational deviations are found on their respective interface with ACE2. The most significant change can be seen in the middle bridge, The most prominent alteration is the substitution of Val404 in the SARSRBD with Lys417 in the nCoV RBD ${ }^{[19]}$, This may also be the main reason for its increased affinity. Through the results of molecular docking, we found that the main binding site between alkaloids and human ACE2 protein is in the middle bridge, namely D30、H34. This also confirmed our conjecture to some extent that alkaloids and stilbenes may have synergistic effect on the anti-2019nCoV virus.

Next, we select the two compounds with the lowest binding energy and analyze their molecular models. Molecular docking results showed that pseudojervine and D30 of human ACE2 were mainly combined in the form of hydrogen bonds and had good binding activity, which indicated that pseudojervine could hinder the binding of 2019-nCoV S-protein RBD domain and ACE2 at D30. Imperialine-3- $\beta$-D-glucoside combines with ACE2 H34 in the form of hydrogen bonds. which indicates that Imperialine-3- $\beta$-D-glucoside can hinder the binding of 2019-nCoV S-protein RBD domain and ACE2 at H34. The above results show that the combination of pseudojervine and Imperialine-3- $\beta$-D-glucoside will probably block the binding of ACE2 and S-protein. (Supporting Information Figure S4-S6). 


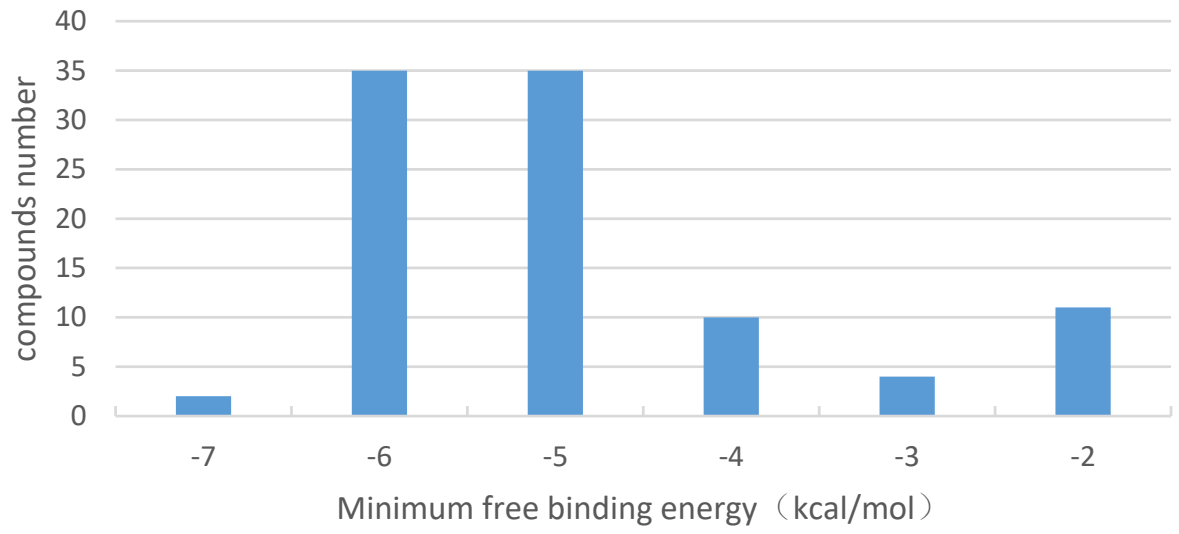

Fig. S3 Distribution of the lowest binding free energy of the candidate compounds

Table S3 Binding energy value of candidate compounds (Top 20)

\begin{tabular}{|c|c|c|c|}
\hline Active order & compound & locus & $\begin{array}{l}\text { binding } \\
\text { energy }\end{array}$ \\
\hline 1 & hupehemonside & $\mathrm{H} 34$ & -7.1 \\
\hline 2 & Imperialine-3- $\beta$-D-glucoside & H34 & -7.1 \\
\hline 3 & pseudojervine & D30 & -6.8 \\
\hline 4 & zhebeininoside & H34 & -6.8 \\
\hline 5 & Veratroylzygadenine & D30 H34 & -6.8 \\
\hline 6 & Zhebeinone-3- $\beta$-D-glucoside & $\mathrm{H} 34$ & -6.7 \\
\hline 7 & Mulberroside E & D30 & -6.7 \\
\hline 9 & Hupehenisine & D30 & -6.6 \\
\hline 10 & verdine & D30 & -6.6 \\
\hline 12 & verticinone-3- $\beta$-D-glucoside & $\mathrm{H} 34$ & -6.6 \\
\hline 13 & (E)-Resveratrol 3,5-O- $\beta$-diglucoside & D30 & -6.6 \\
\hline 15 & peimisine & D30 & -6.4 \\
\hline 16 & 15-O-(2-Methylbutanoyl)-3-O-veratroylprotoverine & D30 & -6.4 \\
\hline 17 & 3-Acetylzygadenine & D30 & -6.4 \\
\hline 18 & Polydatin IV & D30 & -6.4 \\
\hline 19 & Piceatannol 3,4'-di- $\beta$-D-glucopyranoside & Q42 & -6.4 \\
\hline 20 & puqietinone & H34 & -6.3 \\
\hline
\end{tabular}

\section{Discussion}

The clinical manifestations of 2019-nCoV are fever, fatigue and dry cough. Because of the 
cytokine storm caused by the invasion of of $2019-\mathrm{nCoV}$ and the poor tolerance of patients, the application of high doses of glucocorticoids leads to serious sequelae. Critically ill patients usually developed dyspnea, acute respiratory distress syndrome, septic shock, metabolic acidosis, hemorrhage and coagulation dysfunction gradually one week after onset, some or even dead; Patients with mild symptoms may not have fever. The 2019-nCoV was found to be the seventh coronavirus that can infect humans. It is also the third coronavirus that causes severe pandemic and severe respiratory diseases following severe acute respiratory syndrome (SARS) and Middle East respiratory syndrome (MERS) in the past 20 years. Compared with SARS, 2019-nCoV has higher infectivity and variability which can spread without symptoms.It's not only affects the lungs, but also causes damage to kidney, heart, liver and other organs that leading to systemic organ exhaustion, and there is also a phenomenon that a return to the 2019-nCoV-positive after treatment.

However, the vaccine development process usually takes months or even years. It may take a long time before its clinical application even though the vaccine research against $2019-\mathrm{nCoV}$ is being carried out in various countries. Nearly 100 clinical medication trials related to 2019-nCoV had been registered in the national clinical trial registry, but there were no specific therapeutic drugs and preventive drugs with definite curative effect so far.

In this context, promoting the establishment of $2019-\mathrm{nCoV}$ in vitro and in vivo models, screening anti-2019-nCoV drugs, studying on antiviral mechanism and providing laboratory data for clinical recommended drugs are of great significance to fight against the epidemic at this stage.

Computer Aided Drug Design has the characteristics of high speed and low cost, which is suitable for the screening of chemical components in large-scale production of traditional Chinese medicine. Scientists have used molecular docking technology to screen out a large number of potential pharmaceutical ingredients from traditional Chinese Medicine. Cinatl $\mathrm{j}$ et al ${ }^{[22]}$ analyzed the coronavirus isolated from SARS patients in the clinical center of Frankfurt University in Germany, evaluated the antiviral potential of Ribavirin, 6-azauridine,Pyrazomycin, Mycophenolic acid and Glycyrrhizin, and found that glycyrrhizin was not only inhibited the replication of SARS$\mathrm{CoV}$, but also inhibited the adsorption and penetration of SARS-CoV. According to the literature reports, the extract from Isatis tinctoria and its chemical components Indigo, Sinapiside, Aloe emodin and Hesperidin ${ }^{[23]}$; Houttuyniae Herba extract ${ }^{[24]}$; two kinds of Cibotii Rhizoma extract ${ }^{[25]}$; Amentoflavone isolated from Torreya nucifera (L.) Sieb. et Zucc ${ }^{[26]}$ have obvious inhibitory effect 
on SARS-CoV 3CLpro. These studies provid scientific and theoretical basis for the treatment of 2019-nCoV with Chinese Medicine and reveal the feasibility of traditional Chinese medicine as an auxiliary drug of chemical drugs at the molecular level.

Mongolian medicine have the same origin as traditional Chinese medicine, but its application is less developed and utilized. The medicine used in this research institute is called Agsirga, the dried roots and rhizomes of wild Veratrum nigrum L. of Inner Mongolia, is a traditional Mongolian medicine commonly used to treat tumor and cancer in the characteristic "Purgative therapy" of Mongolian medicine. Agsirga mainly contains alkaloids, flavonoids, stilbenes, organic acids, saponins, etc, among which steroidal alkaloid is the main active components. These alkaloid can temporarily increase $\mathrm{ca}^{2+}$ current, prolong action potential duration, enhance myocardial contractile function, and improve the cardiac overload state in hypertension ${ }^{[27]}$.

Veratrum alkaloids can lower blood pressure in rats, rabbits, cats and rats with renal hypertension in varying degrees, with fast and strong effect in a dose-dependent manner. Its hypotensive effect may be related to its central effect and direct vasodilation action ${ }^{[28]}$. Chen Shizhong et al. ${ }^{[29]}$ have found that veratrum alkaloids have anti transplanted hepatoma activity in mice, and have a strong inhibitory effect on the proliferation of human breast cancer cells MCF7, MDA 468. Cyclopamine, one of the mesofenamine alkaloids, has shown good antitumor potential due to its specific blocking effect on hedgehog signaling pathway. The research on cyclopamine has become a hotspot in the field of anticancer ${ }^{[30]}$ Veratrum alkaloids also have antifungal effects. Its aqueous extract (1:4) Have strong bacteriostatic action to dermatophyte in varying degrees, such as Trichophyton violaceum, Trichophyton concentric, Xanthomonas schlegeli, Microsporum audouinii, Epidermophyton inguinale Nocardia asteroides and also Mycobacterium tuberculosis.

Based on HPLC-MS technology, the potential anti-2019-ncov chemical components in Mongolian medicine Agsirga were quickly separated and identified in this research. In combination with molecular docking technology, the identified compounds were virtual screened with $\triangle \mathrm{g}<-6.0$ $\mathrm{kcal} \cdot \mathrm{mol}^{-1}$ as a potential anti-2019-ncov infection active ingredent and 37 potential effective components were screened out, which provided scientific basis for further development and utilization of Mongolian medicine Agsirga.

To sum up, the core active compounds alkaloids of Agsirga have been explored to block the binding of 2019-nCoV S-protein and ACE2 by molecular docking technology. It provides a 
reference for the further development of Mongolian medicine treatment for 2019-nCoV epidemic.However, the obtained results may have deviations because of the lack of consideration of the content of chemical components, insufficient understanding of viruses and diseases, or limitations of molecular docking itself. The research should also be verified Later at multiple levels through pharmacodynamic evaluation, metabonomics, single target, etc.

\section{Conclusions}

The research combining HPLC-MS with molecular docking was conducted which got a conclusion that there are potential active substances in Mongolian medicine Agsirga which can block the binding of ACE2 at the molecular level, all of them can be used as potential inhibitors of 2019-nCoV for further research and development. The relevant research results of this experiment will provide theoretical basis for Mongolian medicine Agsirga potential active substances anti2019-nCoV, as well as methodological reference for the study of the mechanism of antiviral active components of Mongolian medicine.

\section{Acknowledgements:}

This work was funded by National Science Foundation of China (81460651 to Baoquan Bao)

\section{Thanks:}

The structure of the full-length human ACE2 bound to the RBD of the 2019-nCoV provided by Zhou Qiang team of West Lake University 


\section{References}

1. LIU QY; WANG XL (2019) Strategies for the development of drugs targeting novel coronavirus 2019-nCoV. Acta Pharmaceutica Sinica 1-17[2020-03-06].

2. Chine Yu, Jiuwang; Wang, Lu; Bao, Lidao (2020): Exploring the Active Compounds of Traditional Mongolian Medicine in Intervention of Novel Coronavirus (2019-nCoV) Based on Molecular Docking Method. ChemRxiv. Preprint. https://doi.org/10.26434/chemrxiv.11882838.v1se

3. Chinese Materia Medica Editorial Board., ed., 2004, Chinese materia medica·Mongolian medicine roll, Shanghai Science and Technology Press, Shanghai, China, pp.413-415

4. Docherty J J, Fu M M, Stiffler B S, et al. (1999) Resveratrol inhibition of herpes simplex virus replication [J]. Antiviral Res, 43(3): 145-155.

5. Li MK, Liu YY, Xiong HR (2015) Pharmacodynamic Analysis of Emodin Combined with Resevertrol to Against HSV-1[J]. Journal of New Medicine, 2015(25):23.

6. Evers D L, Wang X, Huong S M, et al. (2004) 3, 4', 5-Trihydroxytrans-stilbene (resveratrol) inhibits human cytomegalovirus replication and virus-induced cellular signaling [J]. Antiviral Res,,63(2): 8595.

7. Lin HC, Chen YF, Hsu WH, et al. 2012 Resveratrol helps recovery from fatty liver and protects against hepatocellular carcinoma induced by hepatitis B virus $\mathrm{X}$ protein in a mouse model [J] Cancer Prev Res (Phila), 5(7): 952-962.

8. Zhou X, Lu QJ, Wang L, et al. (2005) Inhibitory effect of resveratrol and its derivatives on HBV in vitro, Chinese Pharmaceutical Journal, 40(24) : 1904-1906

9. Wang YT, Zhao SS, Guan WD, et al. The Inhibitory Effect of Resveratrol on Common Enteroviruses [J]. Journal of New Chinese Medicine, 2015, 47 (2): 222-224.

10. Zhang L, Li Y, Gu Z, et al. (2015) Resveratrol inhibits enterovirus 71 replication and proinflammatory cytokine secretion in rhabdosarcoma cells through blocking IKKs/NF- $\mathrm{KB}$ signaling pathway [J]. PLoS One, 10(2): e0116879.

11. Clouser C L, Chauhan J, Bess M A, et al. (2012) Anti-HIV-1 activity of resveratrol derivatives and synergistic inhibition of HIV-1 by the combination of resveratrol and decitabine [J]. Bioorg Med Chem Lett, 22(21): 6642-6646.

12. Rawson J M, Roth M E, Xie J, et al. (2016) Synergistic reduction of HIV-1 infectivity by 5azacytidine and inhibitors of ribonucleotide reductase.Bioorg Med Chem, 24(11) : 2410-2422.

13. Lee S, Yoon K D, Lee M, et al. (2016) Identification of a resveratrol tetramer as a potent inhibitor of hepatitis C virus helicase [J]. Br J Pharmacol, 173(21) : 191-211.

14.Han Y S, Penthala N R, Oliveira M, et al. (2016) Identification of resveratrol analogs as potent anti-dengue agents using a cell-based assay [J]. J Med Virol, Epub ahead of print.

15. Palamara A T, Nencioni L, Aquilano K, et al. Inhibition of influenza A virus replication by resveratrol [J]. J Infect Dis, 19 (10): 1719-1729.

16. Li J; Ma XB; Shen J; et al. (2020) Screening of active components from traditional Chinese medicine against novel coronavirus based on literature mining and molecular docking, Chinese Traditional and Herbal Drugs. $1-6$ [2020-03-06]. http://kns.cnki.net/kcms/detail/12.1108.R.20200218.1239.008.html.

17. Niu M, Wang RL, Wang ZX, et al. (2020) Rapid establishment of traditional Chinese medicine prevention and treatment for the novel coronavir pneumonia based on clinical experience and 
molecular docking [J/OL], China Journal of Chinese Materia Medica, 1-8[2020-03-06]. https://doi.org/10.19540/j.cnki.cjemm.20200206.501.

18. Yu ZL, Zixian Zhao, Yujia Wang1, Yueqing Zhou, et al. 2020, Single-cell RNA expression profiling of ACE2, the putative receptor of Wuhan 2019-nCov,bioRxiv

19. Yan R, Zhang Y, Guo Y, et al. Structural basis for the recognition of the 2019-nCoV by human ACE2[J]. bioRxiv, 2020.

20. Chinese researchers have found three existing drugs with fairly good inhibitory effects on the novel coronavirus (2019-nCoV) at the cellular level http://www.cas.cn/cm/202002/t20200204_4733435.shtml

21. Tang Jian. Discovery and structural modification of antitumor active components of xing 'an veratrol [D]. SJTU, 2008.

22. CINATL J, GENSTEN B, BAUER G, et al. Glycyrrhizin, an active component of liquorice roots, and replication of SARS -associated coronavirus [J]. Lancet, 2003, 361: 2045.

23. LIN C W, TSAI F J, TSAI C H, et al. Anti-SARS coronavirus 3C-like protease effects of isatis indigotica root and plant -derived phenolic compounds[J]. Antivir Res, 2005, 68(1): 36.

24. LAU K M, LEE K M, KOON C M, et al. Immunomodulatory and anti-SARS activities of Houttuynia cordata[J]. J Ethnopharmacol, 2008, 118(1): 79.

25. WEN C C, SHYUR L F, JAN J T, et al. Traditional Chinese medicine herbal extracts of Cibotium barometz, Gentiana scabra, Diosc orea batatas, Cassia tora, and Taxillus chinensis inhibit SARSCoV replication[J]. J Tradit Complementary Med, 2011, 1(1): 41.

26. RYU Y B, JEONG H J, KIM J H, et al. Biflavonoids from Torreya nucifera displaying SARS -CoV 3CLpro inhibition[J]. Bioorgan Med Chem, 2010, 18(22): 7940.

27. Wang J M, Wei Yuan, Zhong Ci, et al. Effects of wusuli veratrol alkaloid on action potential and calcium current in guinea pig cardiac myocytes. Acta Academiae Medicinae Militaris Tertiae, 2001, 23(12):1403-1405.

28. Liu Yan, Gao Guang You, et al. Antihypertensive effect of photolithoxyline. Journal of dalian medical university, 1991,13(4): 68-71.

29. Xu Guo Jun, Xu Luo Shan, et al. Classification and quality study of commonly used Chinese medicinal materials (volume 4). Fujian science and technology press, 2001, 121-178.

30. Zhou Jian Xia, Kang Lu, et al. Progress in the study of isosteroidal alkaloid - cyclopamine. China natural medicine, 2006, 4(6): 468-472.

31. ZHANG BING, Dong Xin et al. Rapid separation and identification of chemical components of veratrol by uplc-q-tof /MS [J]. Academic Journal of Second Military Medical Universit, 2012(05):7881.

32. Zhou J L, Xin G Z, Shi Z Q , et al. Characterization and identification of steroidal alkaloids in Fritillaria species using liquid chromatography coupled with electrospray ionization quadrupole time-of-flight tandem mass spectrometry[J]. Journal of Chromatography A, 2010, 1217(45):71097122 .

33. Yuan Du, Zu-Guo Zheng, Yue Yu. Rapid discovery of cyclopamine analogs from Fritillaria and Veratrum plants using LC-Q-TOF-MS and LC-QqQ-MS[J]. Journal of Pharmaceutical \& Biomedical Analysis, 2017, 142:201.

34. Laurila, Jaana, Laakso, Into, V??n?nen, Tiina,. Determination of Solanidine- and Tomatidine-Type Glycoalkaloid Aglycons by Gas Chromatography/Mass Spectrometry[J]. J Agric Food Chem, 47(7):2738-2742. 
35. V. V. Kul'kova, R. Shakirov, AL D'yakonov. Steroid alkaloids of the plant and animal Kingdoms[J]. Chemistry of Natural Compounds, 1999, 35(2):107-149.

36. Atta-ur-Rahman, Rahat Azhar Ali, Tahira Parveen, 等. Alkaloids from Veratrum album[J]. Phytochemistry, 1991, 30(1):368-370.

37. R. N. Nuriddinov, A. I. Saidkhodzhaev, S. Yu. Yunusov. The structure of korsine[J]. Chemistry of Natural Compounds, 1968, 4(3):139-144.

38. Li, Yan, Yili, A, Muhamat, Aziz, 等. A New Alkaloid with Tracheal Relaxant Effect from the Bulbs of Fritillaria pallidiflora[J]. Chemistry of Natural Compounds.

39. Kim, Min Kyoung, Cha, Kyu-Min, Hwang, Seock-Yeon, et al.. Pectinase-treated \r, Panax ginseng $\backslash \mathrm{r}$, protects heat stress-induced testicular damage in rats[J]. Reproduction, 153(6):737-747.

40. Li H L, Tang J, Liu R H , et al. Characterization and identification of steroidal alkaloids in the Chinese herb Veratrum nigrum L. by high-performance liquid chromatography/electrospray ionization with multi-stage mass spectrometry[J]. Rapid Communications in Mass Spectrometry, 2010, 21(6):869-879.

41. Lang Zhao, Zhi Qiang Ou, et al. Study on steroid alkaloids in xing 'an veratrol [J]. Journal of Chinese Materia Medica (23):65-68.

42. Cong Y , Wang J H, Wang R, et al. A study on the chemical constituents of Veratrum nigrum L. processed by rice vinegar[J]. 2008.

43. Esteb J J, Mcnulty L A M, O'Reilly S A, et al. NMR Spectroscopy: A Critical Piece of the Spectroscopy-Centered Synthetic Curriculum[M]// NMR Spectroscopy in the Undergraduate Curriculum: Upper-Level Courses and Across the Curriculum Volume 3. 2016.

44. DONG JING,WANG HONG, et al. High performance liquid chromatography/electrospray - ion trap - time of flight mass spectrometry analysis to identify the main chemical components in Chinese traditional medicine polygonum cuspidatum [J]. chromatography, 2009(04):50-55.

45. Vastano B C, Chen Y, Zhu N, et al. Isolation and Identification of Stilbenes in Two Varieties of Polygonum c uspidatum[J]. Journal of Agricultural and Food Chemistry, 2000, 48(2):253-256.

46. Hongjiao D, et al. High resolution mass spectrometry combined with four-stage bar and electrostatic field track well for rapid analysis of chemical components of ethnic medicine rhubarb [J]. Chinese herbal medicine, 2016, Vol.47Issue(14):2428-2435.

47. You cai Hu. Study on the active components of flower stem husk by short calyx instrument based on active screening and chemical screening [D]. Chinese Peking Union Medical College, 2008.

48. NONAKA, GENICHIRO, MINAMI, MASAFUMI, NISHIOKA, ITSUO. Studies on Rhubarb (Rhei Rhizoma). III. Stilbene Glycosides[J]. Chemical \& Pharmaceutical Bulletin, 25(9):2300-2305.

49. Xue Xun We. Analysis of chemical composition of chengqi decoction [D]. Zhejiang University, 2015.

50. Yan Min Wang. Study on the chemical composition of Chinese jujube [D]. Henan College of Traditional Chinese Medicine2014.

51. Li Na Zhang, Man Liu, et al. Simultaneous determination of glutamate and arginine in human plasma by lc-ms /MS method [J]. Chinese Journal of Pharmaceutical Analysis, 2015, 21(7):11721178 .

52. Peng Yang, Zhi Xing Qing, et al. Identification of isoquinoline alkaloids in celandine by hplc-q-tof /MS [J]. Modern Chinese Medicine .

53. Hai-Bo Zhou, et al. Citric acid in wine samples was determined by ion chromatography-mass spectrometry (IC/MS) [J]. Journal of food safety and quality inspection, 2013(6):1835-1840. 
54. Ting Gui Zhang, et al. Simultaneous determination of inositol and quinic acid in tobacco by liquid chromatography-tandem mass spectrometr [J]. The Chinese test, 2019(7).

55. Clemens Schwarzinger, Ildiko Tanczos, Harald Schmidt, 等. THM-GC/MS analysis of model uronic acids of pectin and hemicelluloses[J]. Journal of Analytical \& Applied Pyrolysis, 2003, 69(1):151-162.

56. Harris $\mathrm{T}$ M, Hay $\mathrm{J}$ V, Quarterman E. Isolation of 2-(4-hydroxybenzyl)malic acid from Petalostemon gattingeri[J]. 1974, 5(13):no-no. 


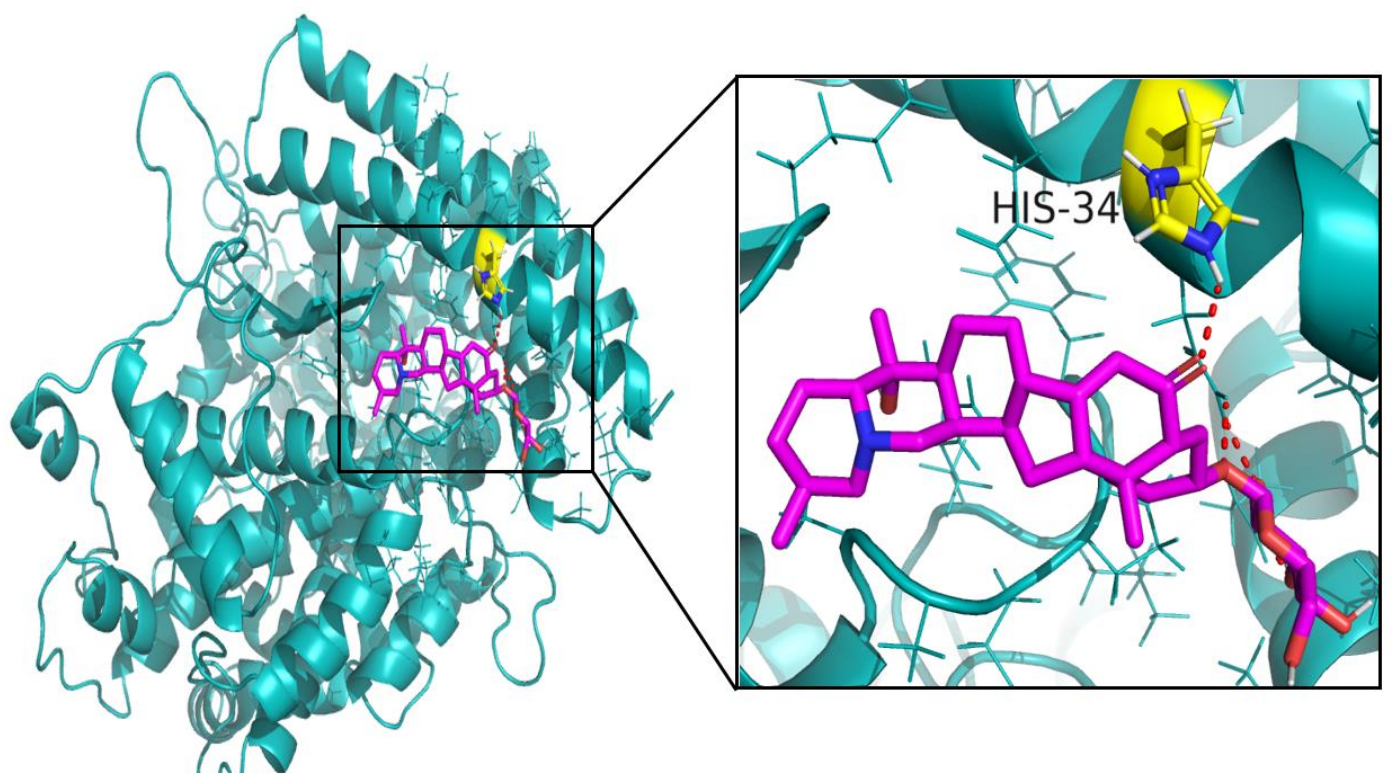

Fig S4: the molecular docking between Imperialine-3- $\beta$-D-glucoside and ACE2. Imperialine-3- $\beta$-D-glucoside and HIS34 in ACE2 are bonded to each other through hydrogen bonds;

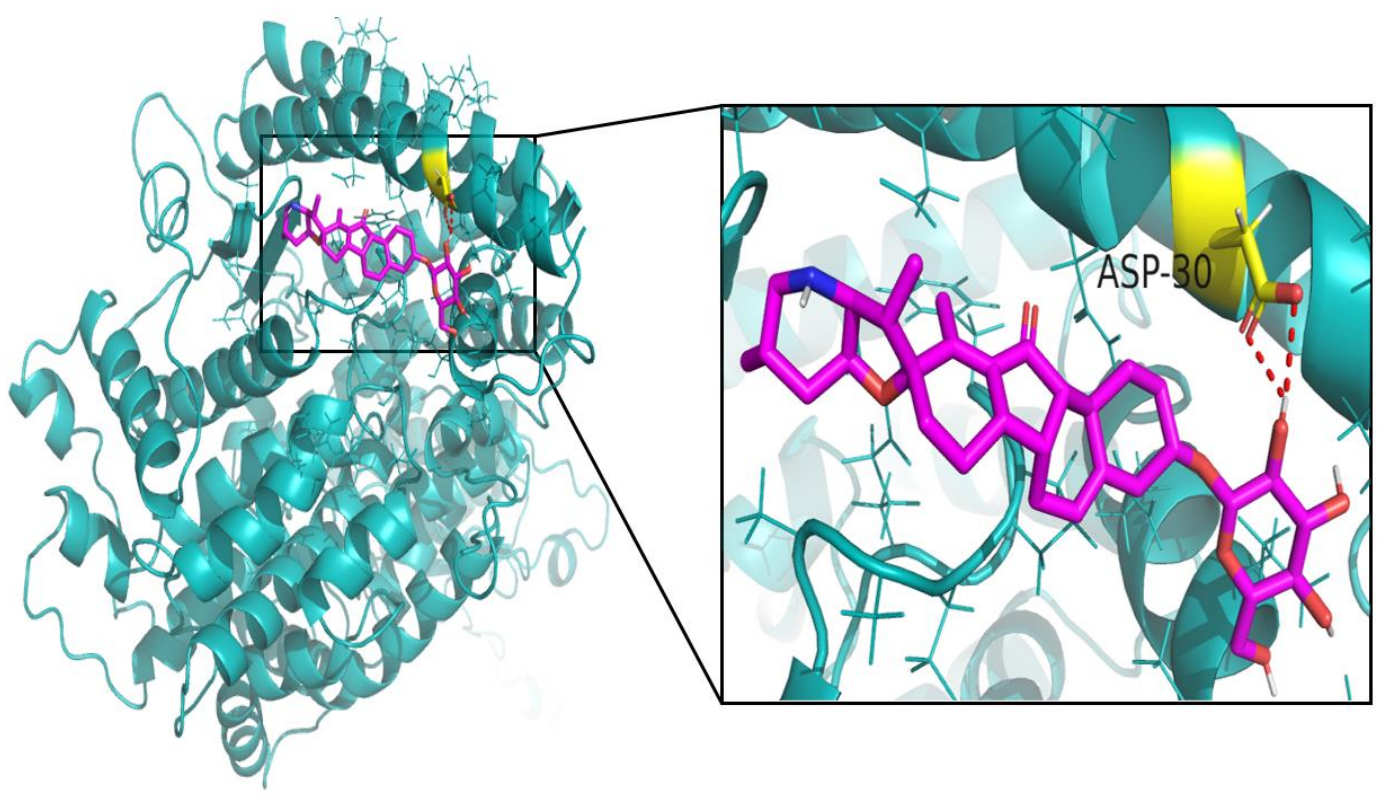

Fig S5: The binding situation of pseudojervine and ACE2, and the pseudojervine interacts with D30 in ACE2 through hydrogen bonds. 


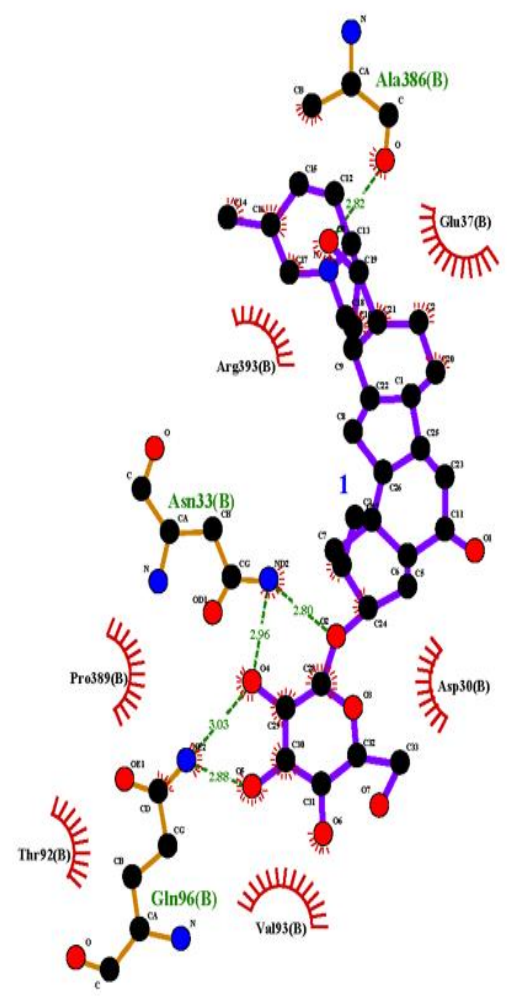

Imperialine-3-B-D-glucoside interacted with residues

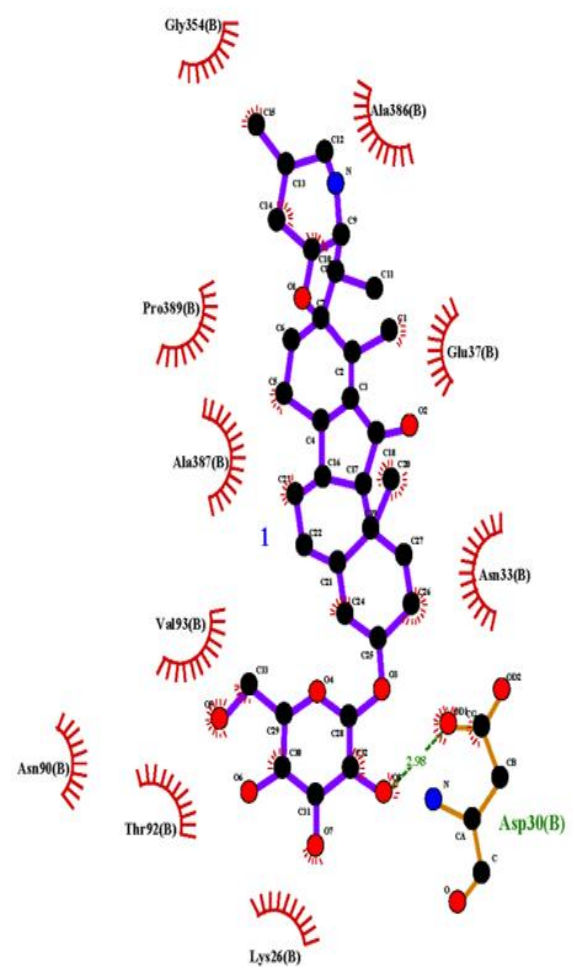

pseudojervine interacted with residues

Fig S6 : Two-dimensional graph of interaction between ACE2 protein Imperialine-3- $\beta$-D-glucoside and pseudojervine 
Table S1 identification of alkaloid constituents of Mongolian medicine ageshiriga by HPLC-Q-Exactive-MS/MS analysis (positive ion mode)

\begin{tabular}{|c|c|c|c|c|c|c|c|c|}
\hline \multirow{2}{*}{ No. } & \multirow{2}{*}{$\begin{array}{l}\mathrm{tR} / \mathrm{mi} \\
\mathrm{n}\end{array}$} & \multirow{2}{*}{ Compounds } & \multirow{2}{*}{$\begin{array}{l}\text { Molecular } \\
\text { formula }\end{array}$} & \multicolumn{2}{|c|}{$[\mathrm{M}+\mathrm{H}]+$ ion, $\mathrm{m} / \mathrm{z}$} & \multirow{2}{*}{ Error } & \multirow{2}{*}{ fragment ion } & \multirow{2}{*}{ Ref } \\
\hline & & & & theoretical & measured & & & \\
\hline 1 & 13.20 & Resveratrol & $\mathrm{C} 14 \mathrm{H} 12 \mathrm{O} 3$ & 229.0859 & 229.0860 & 0.077 & $\begin{array}{c}229.0860 、 211.0754 、 135.0444 、 107.0496 、 193.0648 、 \\
165.0700 、 183.0809 、 119.0495\end{array}$ & Standard \\
\hline 2 & 10.87 & Oxyresveratrol & $\mathrm{C} 14 \mathrm{H} 12 \mathrm{O} 4$ & 245.0808 & 245.0808 & -0.024 & $\begin{array}{c}245.0809 、 227.0699 、 199.0754 、 203.0228 、 161.0597 、 \\
135.0440 、 221.0331 、 181.0650 、 107.0495\end{array}$ & Standard \\
\hline 3 & 9.44 & piceid & $\mathrm{C} 20 \mathrm{H} 22 \mathrm{O} 8$ & 391.1387 & 391.1386 & -0.001 & $\begin{array}{c}229.0859 、 211.0763 、 183.0812 、 135.0443 、 149.0233 、 \\
119.0439 、 107.0495 、\end{array}$ & Standard \\
\hline 4 & 17.16 & veralosidine & $\mathrm{C} 27 \mathrm{H} 43 \mathrm{NO} 2$ & 414.3366 & 414.3366 & 0.033 & $\begin{array}{c}414.3366 、 253.1948 、 126.1279 、 124.1131 、 396.3262 、 \\
98.0958 、 55.0553\end{array}$ & 31 \\
\hline 5 & 6.80 & puqienine $\mathrm{A}$ & $\mathrm{C} 28 \mathrm{H} 47 \mathrm{NO} 3$ & 446.3628 & 446.3633 & 0.145 & $\begin{array}{c}446.3626 、 428.3412 、 98.0966 、 128.1076 、 253.1977 、 \\
81.0703 、 107.0865\end{array}$ & 32 \\
\hline 6 & 7.54 & puqienine $\mathrm{C}$ or puqienine $\mathrm{D}$ & $\mathrm{C} 28 \mathrm{H} 45 \mathrm{NO} 4$ & 460.3421 & 460.3421 & 0.012 & $460.3421 、 442.3266 、 128.1101 、 98.0922 、 424.3122$ & 32 \\
\hline 7 & 8.31 & puqienine $\mathrm{C}$ or puqienine $\mathrm{D}$ & $\mathrm{C} 28 \mathrm{H} 45 \mathrm{NO} 4$ & 460.3421 & 460.3426 & 0.193 & 460.3427、128.1078、98.0946、128.1066、124.1125 & 32 \\
\hline 8 & 16.77 & veratramine & $\mathrm{C} 27 \mathrm{H} 39 \mathrm{NO} 2$ & 410.3053 & 410.3058 & 0.185 & $\begin{array}{c}410.3058 、 114.0917 、 392.2953 、 84.0814 、 142.1227 、 \\
\text { 295.2058、225.8624、171.1161、84.0813 }\end{array}$ & Standard \\
\hline 9 & 12.35 & veratrosine & $\mathrm{C} 33 \mathrm{H} 49 \mathrm{NO} 7$ & 572.3581 & 572.3594 & -1.028 & 572.3594、457.2593、84.0814、142.1230、114.0917、 & Standard \\
\hline 10 & 13.49 & puqienine $\mathrm{B}$ & $\mathrm{C} 28 \mathrm{H} 45 \mathrm{NO} 3$ & 444.3472 & 444.3472 & 0.045 & $\begin{array}{c}444.3472 、 105.0685 、 128.1101 、 426.3277 、 98.0914 、 \\
93.0711 、 147.1168\end{array}$ & 33 \\
\hline 11 & 14.61 & puqietinone & $\mathrm{C} 28 \mathrm{H} 47 \mathrm{NO} 2$ & 430.3679 & 430.3675 & 0.156 & $430.3695 、 128.1101 、 412.3635 、 95.0855 、 81.0766 、$ & 35 \\
\hline
\end{tabular}




\begin{tabular}{|c|c|c|c|c|c|c|c|c|}
\hline 12 & 20.66 & N-demethylpuqietinone & $\mathrm{C} 27 \mathrm{H} 45 \mathrm{NO} 2$ & 416.3523 & 416.3503 & -1.419 & 416.3503、398.3477、131.0874、81.0766、98.0984 & 32 \\
\hline 13 & 11.74 & puqietinonoside & $\mathrm{C} 34 \mathrm{H} 57 \mathrm{NO} 7$ & 592.4207 & 592.4196 & -3.114 & $\begin{array}{c}592.4196 、 128.1101 、 430.3636 、 69.0855 、 142.1569 、 \\
412.3569\end{array}$ & 32 \\
\hline 14 & 13.2 & peimisine & $\mathrm{C} 27 \mathrm{H} 41 \mathrm{NO} 3$ & 428.3159 & 428.3142 & -0.861 & $\begin{array}{c}428.3142 、 410.30577 、 114.0915 、 67.0549 、 84.0814 、 \\
109.1025 、 81.0711 、 93.0697\end{array}$ & 33 \\
\hline 15 & 16.66 & Hupehenisine & $\mathrm{C} 27 \mathrm{H} 41 \mathrm{NO} 3$ & 428.3159 & 428.3140 & -1.146 & $\begin{array}{r}428.3156 、 410.4457 、 \begin{array}{l}114.0965 、 392.1255 、 84.0851 、 \\
124.0977\end{array}\end{array}$ & 35 \\
\hline 16 & 6.97 & verdine & C27H41NO5 & 460.3057 & 460.3039 & -0.915 & $\begin{array}{c}460.3057 、 114.0961 、 442.2945 、 95.2148 、 81.3569 、 \\
67.6432 、 84.0813 、 109.1014 、 、 126.1278 、 293.1896 、 \\
241.1040\end{array}$ & Standard \\
\hline 17 & 15.51 & jervine & C27H39NO3 & 426.3002 & 426.2987 & -0.52 & $\begin{array}{c}426.2987 、 114.0961 、 408.3011 、 124.9520 、 149.0960 、 \\
210.1442 、 266.2279 、 313.2155 、 351.2290 、 102.0915 、 \\
126.1278 、 84.0812\end{array}$ & Standard \\
\hline 18 & 11.08 & pseudojervine & C33H49NO8 & 588.3530 & 588.3057 & 0.603 & $\begin{array}{c}114.0961 、 426.3011 、 408.3026 、 124.9517 、 84.0811 、 \\
109.1013 、 570.3410 、 518.9392 、 275.1027 、 397.2942 、 \\
163.0335 、 142.1365\end{array}$ & Standard \\
\hline 19 & 14.06 & veratvirine & $\mathrm{C} 27 \mathrm{H} 41 \mathrm{NO} 4$ & 444.3108 & 444.3114 & 1.48 & $\begin{array}{c}\text { 114.0961、426.2964、124.1146、408.2922、84.0813、 } \\
92.7212 、 109.1014 、 121.1020 、 126.1280 、 158.1519 、 \\
\text { 295.2062 }\end{array}$ & Standard \\
\hline 20 & 17.55 & Cyclopamine & $\mathrm{C} 27 \mathrm{H} 41 \mathrm{NO} 2$ & 412.3210 & 412.3213 & 0.76 & $\begin{array}{c}114.0961 、 114.0911 、 85.0524 、 81.0342 、 109.0286 、 \\
98.0969 、 126.1276 、 164.9211 、 396.3261 、 364.3001 、 \\
\text { 313.1528、251.1791、 }\end{array}$ & 33 \\
\hline
\end{tabular}




\begin{tabular}{|c|c|c|c|c|c|c|c|c|}
\hline 21 & 18.33 & methyljervine-N-3'-propanoate & $\mathrm{C} 31 \mathrm{H} 45 \mathrm{NO} 5$ & 512.3370 & 512.3356 & -2.55 & $512.3356 、 114.0961 、 124.9500 、 408.3022$ & 36 \\
\hline 22 & 21.35 & solanidin & $\mathrm{C} 27 \mathrm{H} 43 \mathrm{NO}$ & 398.3417 & 398.3408 & 1.058 & $\begin{array}{c}398.3408 、 380.2946 、 126.1276 、 150.3362 、 \\
204.6659 、 213.1628\end{array}$ & 32 \\
\hline 23 & 24.56 & Demissidine & $\mathrm{C} 27 \mathrm{H} 45 \mathrm{NO}$ & 400.3573 & 400.3584 & 1.066 & $\begin{array}{c}400.3584 、 382.3458 、 98.0969 、 150.3362 、 204.6653 、 \\
248.1434 、 91.8098\end{array}$ & 34 \\
\hline 24 & 20.50 & Tomatidine & $\mathrm{C} 27 \mathrm{H} 45 \mathrm{NO} 2$ & 416.3523 & 416.3509 . & 0.769 & $\begin{array}{c}416.3523 、 398.3437 、 99.0809 、 114.0549 、 138.0548 、 \\
\text { 248.1434、91.8098、69.0705、 }\end{array}$ & 34 \\
\hline 25 & 19.97 & Solasodine, acetate & $\mathrm{C} 29 \mathrm{H} 45 \mathrm{NO} 3$ & 456.3472 & 456.3463. & 1.02 & $\begin{array}{c}456.3463 、 396.3253 、 112.0760 、 114.0588 、 138.0569 、 \\
248.1434 、 130.0864 、 69.0769 、\end{array}$ & 34 \\
\hline 26 & 25.35 & Solasodine & $\mathrm{C} 27 \mathrm{H} 43 \mathrm{NO} 2$ & 414.3366 & 414.3357 & 0.99 & $\begin{array}{c}414.3357 、 396.3299 、 98.0968 、 114.0912 、 138.8181 \text { 、 } \\
69.0705\end{array}$ & 35 \\
\hline 27 & 17.78 & Rubijervin or isorubijervine & $\mathrm{C} 27 \mathrm{H} 43 \mathrm{NO} 2$ & 414.3366 & 414.3352 & -0.114 & $\begin{array}{c}414.3352 、 396.3269 、 150.1278 、 396.3246 、 204.1756 、 \\
81.0698 、\end{array}$ & 35 \\
\hline 28 & 18.31 & Rubijervine or isorubijervine & $\mathrm{C} 27 \mathrm{H} 43 \mathrm{NO} 2$ & 414.3366 & 414.3355 & 0.474 & $\begin{array}{c}414.3352 、 396.3269 、 150.1278 、 396.3246 、 204.1756 、 \\
81.0698 、\end{array}$ & 35 \\
\hline 29 & 17.41 & puqietinedinone & $\mathrm{C} 28 \mathrm{H} 45 \mathrm{NO} 2$ & 428.3523 & 428.3540 & -0.344 & $\begin{array}{c}\text { 428.3540、410.3042、 } 81.0711 、 69.0623 、 95.0896 、 \\
93.0681\end{array}$ & 32 \\
\hline 30 & 16.94 & ebeiedinone & $\mathrm{C} 27 \mathrm{H} 43 \mathrm{NO} 2$ & 414.3366 & 414.3385 & 1.274 & $\begin{array}{c}414.3385 、 98.0969 、 396.3260 、 95.0851 、 119.0851 、 \\
105.0327\end{array}$ & 32 \\
\hline 31 & 19.23 & puqiedinone & $\mathrm{C} 27 \mathrm{H} 43 \mathrm{NO} 2$ & 414.3366 & 414.3368 & 0.597 & $\begin{array}{c}414.33640 、 98.0968 、 396.3260 、 112.1102 、 95.0754 、 \\
105.0327\end{array}$ & 32 \\
\hline 32 & 14.79 & zhebeinone & $\mathrm{C} 27 \mathrm{H} 43 \mathrm{NO} 3$ & 430.3315 & 430.3304 & 0.502 & $\begin{array}{c}430.3389 、 98.0965 、 412.3259 、 396.3841 、 176.2453 、 \\
110.0987 、 148.9963 、 55.7461 、 96.1042\end{array}$ & 32 \\
\hline 33 & 5.74 & pingpeimine $\mathrm{A}$ & $\mathrm{C} 27 \mathrm{H} 45 \mathrm{NO} 5$ & 464.3370 & 464.3361 & 0.955 & 464.3371、446.3166、98.0961、138.1266、124.1123、 & 32 \\
\hline
\end{tabular}




\begin{tabular}{|c|c|c|c|c|c|c|c|c|}
\hline 34 & 13.22 & verticinone $\mathrm{N}$-oxide & $\mathrm{C} 27 \mathrm{H} 43 \mathrm{NO} 4$ & 446.3264 & 446.3256 & -1.489 & $\begin{array}{l}446.3256 、 428.3162 、 98.0961 、 112.1188 、 410.3011 、 \\
384.2977 、 138.1255 、 96.6322 、 82.0644 、 58.0655 \text { 。 }\end{array}$ & 32 \\
\hline 35 & 14.56 & korsine N-oxide & $\mathrm{C} 27 \mathrm{H} 43 \mathrm{NO} 4$ & 446.3264 & 446.3249 & -0.36 & $\begin{array}{c}\text { 446.3249、428.6662、128.1088、98.0916、410.3366、 } \\
95.0833\end{array}$ & 37 \\
\hline 36 & 15.23 & Hupehenirine or hupehenizine & $\mathrm{C} 27 \mathrm{H} 43 \mathrm{NO} 2$ & 414.3366 & 414.3354 & 0.3276 & $\begin{array}{c}\text { 414.3355、98.0969、396.3247、111.1233、98.0911、 } \\
140.6622\end{array}$ & 32 \\
\hline 37 & 16.77 & Hupehenirine or hupehenizine & $\mathrm{C} 27 \mathrm{H} 43 \mathrm{NO} 2$ & 414.3366 & 414.3352 & -0.114 & $\begin{array}{c}\text { 414.3355、98.0969、396.3247、111.1233、98.0911、 } \\
140.6622\end{array}$ & 32 \\
\hline 38 & 11.08 & verticine $\mathrm{N}$-oxide & $\mathrm{C} 27 \mathrm{H} 45 \mathrm{NO} 4$ & 448.3421 & 448.3413 & 1.286 & $\begin{array}{c}\text { 448.3413、98.0969、430.3309、412.9605、138.5132、 } \\
\text { 114.0916、111.1115、98.0970、82.9451 }\end{array}$ & 33 \\
\hline 39 & 20.47 & Puqiedine or ebeiedine & $\mathrm{C} 27 \mathrm{H} 45 \mathrm{NO} 2$ & 416.3523 & 416.3523 & 0.028 & 416.3523、98.0969、398.3377、107.9674、91.0538 & 33 \\
\hline 40 & 19.88 & Puqiedine or ebeiedine & $\mathrm{C} 27 \mathrm{H} 45 \mathrm{NO} 2$ & 416.3523 & 416.3524 & 0.366 & $416.3523 、 98.0969 、 398.3377 、 107.9674 、 91.0538$ & 33 \\
\hline 41 & 12.65 & $\begin{array}{l}\text { Zhebeinone-3- } \beta \text {-D-glucoside or } \\
\text { verticinone-3- } \beta \text {-D-glucoside or } \\
\text { Imperialine-3- } \beta \text {-D-glucoside or } \\
\text { hupehemonside }\end{array}$ & C33H53NO8 & 592.3843 & 592.3822 & -2.332 & 98.0969、574.3722、412.3212、112.1123 & 32、 38 \\
\hline
\end{tabular}


Zhebeinone-3- $\beta$-D-glucoside or verticinone-3- $\beta$-D-glucoside or Imperialine-3- $\beta$-D-glucoside or

hupehemonside

Zhebeinone-3- $\beta$-D-glucoside or

verticinone-3- $\beta$-D-glucoside or Imperialine-3- $\beta-\mathrm{D}$-glucoside or hupehemonside

Zhebeinone-3- $\beta$-D-glucoside or

$44 \quad 15.04$ verticinone-3- $\beta$-D-glucoside or Imperialine-3- $\beta$-D-glucoside or

hupehemonside

46

11.60
C33H53NO8

592.3843

592.3866

5.696

98.0969、574.3722、412.3212、112.1123

32、 38

$47 \quad 6.78 \quad$ Zygadenin or its isomer

594.4

$-0.3360$

594.3967、98.0969、432.2261、414.3374、396.3351

39

494.3112、98.0979、476.3006、458.2890、440.2823、

$$
422.2692
$$

$\mathrm{C} 27 \mathrm{H} 43 \mathrm{NO} 7$

494.3112

494.3098

$-0.0220$

494.3112、98.0979、476.3006、458.2890、440.2823、 


\begin{tabular}{|c|c|c|c|c|c|c|c|c|}
\hline 48 & 16.82 & $\begin{array}{l}\text { 15-O-(2-Methylbutanoyl)-3-O- } \\
\text { veratroylprotoverine }\end{array}$ & $\mathrm{C} 41 \mathrm{H} 59 \mathrm{NO} 13$ & 774.4059 & 774.4030 & -3.1300 & $\begin{array}{c}\text { 774.4030、112.1135、756.3933、574.3366、 } \\
\text { 472.2685、 } 436.2461 、 636.3136\end{array}$ & 41 \\
\hline 49 & 14.77 & verticinone & $\mathrm{C} 27 \mathrm{H} 43 \mathrm{NO} 3$ & 430.3315 & 430.3308 & 1.4240 & $\begin{array}{c}\text { 412.219、430.3308、98.0965、176.5209、158.0914、 } \\
112.1011 、 91.8113 、 71.4900 、 110.0855\end{array}$ & Standard \\
\hline 50 & 17.87 & peimine & $\mathrm{C} 27 \mathrm{H} 45 \mathrm{NO} 3$ & 432.3472 & 432.3482 & 2.277 & $\begin{array}{c}414.33755 、 432.3482 、 112.1077 、 69.0693 、 176.1441 、 \\
98.0969 、 397.14908 、 365.65713 、 158.1719 、 \\
108.7695 、 166.3599\end{array}$ & Standard \\
\hline 51 & 10.32 & Imperialine & $\mathrm{C} 27 \mathrm{H} 43 \mathrm{NO} 3$ & 430.3315 & 430.3310 & -1.1990 & $\begin{array}{c}\text { 412.3220、 } 430.3310 、 98.0965 、 397.1374 、 158.1071 、 \\
\text { 176.1326、109.5145、78.5701、 }\end{array}$ & Standard \\
\hline 52 & 19.20 & Protoveratrine A & $\begin{array}{l}\text { C41H63N } \\
\text { O14 }\end{array}$ & 794.4321 & 794.4321 & -0.0290 & $\begin{array}{c}\text { 776.4194、658.3527、538.4126、478.3699、436.3325、 } \\
112.1126\end{array}$ & 40 \\
\hline 53 & 15.00 & Germinalinine & C39H61NO13 & 752.4215 & 752.4201 & -2.4550 & $\begin{array}{c}\text { 752.4201、98.0969、734.4106、674.3894、572.3194、 } \\
\text { 554.3129、438.2630 }\end{array}$ & 40 \\
\hline 54 & 13.36 & germbudin & C37H59NO12 & 710.411 & 710.4112 & 0.3660 & $\begin{array}{c}\text { 710.4112、98.0969、692.4003、559.3448、456.2740、 } \\
\text { 438.2662、420.2543、98.0970 }\end{array}$ & 40 \\
\hline 55 & 14.46 & Germidine & C34H53NO10 & 636.3742 & 636.3722 & 3.2260 & $\begin{array}{c}\text { 636.3742、618.3635、600.3532、558.3420、98.0969、 } \\
\text { 456.2742、438.2629、420.2521、112.1125 }\end{array}$ & 40 \\
\hline 56 & 19.76 & Verabenzoamine & $\begin{array}{l}\text { C41H59N } \\
\text { O12 }\end{array}$ & 758.411 & 758.4099 & -3.5690 & $\begin{array}{c}\text { 740.3978、758.4099、98.0959、558.3405、456.2727 } \\
\text { 438.2625、420.2517、165.0542、112.1120 }\end{array}$ & 40 \\
\hline 57 & 18.01 & Angeloylzygadenine & $\mathrm{C} 32 \mathrm{H} 49 \mathrm{NO} 8$ & 576.353 & 576.3507 & 0.6160 & $\begin{array}{c}576.3507 、 98.0959 、 558.3411 、 540.3296 、 440.3671 、 \\
422.2966 、 112.1120\end{array}$ & 40 \\
\hline 58 & 15.62 & Veramarine, acetate & $\mathrm{C} 29 \mathrm{H} 45 \mathrm{NO} 4$ & 472.3421 & 472.3410 & 0.6399 & $\begin{array}{c}\text { 472.3410、98.0959、454.3322、430.3081、412.3196、 } \\
394.3090\end{array}$ & 40 \\
\hline 59 & 17.11 & Veratroylzygadenine & C36 H51N & 658.3585 & 658.3563 & -2.0560 & 658.3563、98.0969、622.3352、640.3457、440.2776、 & 42 \\
\hline
\end{tabular}




\begin{tabular}{|c|c|c|c|c|c|c|c|c|}
\hline 60 & 11.32 & 3-Acetylzygadenine & $\mathrm{C} 29 \mathrm{H} 45 \mathrm{NO} 8$ & 536.3217 & 536.3201 & 0.3105 & $\begin{array}{c}536.3201 、 98.0969 、 518.3095 、 102.3998 、 458.2872 、 \\
440.2837 、 422.3658\end{array}$ & 40 \\
\hline 61 & 16.15 & Germerin & $\begin{array}{l}\text { C37H59N } \\
\text { O11 }\end{array}$ & 694.416 & 694.4135 & 4.1060 & $\begin{array}{l}\text { 694.4135、676.40302、618.3635、600.3532、 } \\
\text { 558.3420、456.2742、438.2629、420.2521、112.1125 }\end{array}$ & 40 \\
\hline 62 & 8.18 & Gentiobiose & $\mathrm{C} 12 \mathrm{H} 22 \mathrm{O} 11$ & 365.1054 & $\begin{array}{l}{[\mathrm{M}+\mathrm{Na}]+365.10} \\
511\end{array}$ & -0.1530 & $365.10511 、 203.05251 、 185.04225$ & $34 、 35$ \\
\hline 63 & 14.36 & cue-lure & $\mathrm{C} 12 \mathrm{H} 14 \mathrm{O} 3$ & 229.0835 & $\begin{array}{l}{[\mathrm{M}+\mathrm{Na}]+229.08} \\
59\end{array}$ & 3.589 & 186.9412 & 36 \\
\hline 64 & 6.54 & gentiatibetine & $\mathrm{C} 9 \mathrm{H} 11 \mathrm{NO} 2$ & 166.0862 & 166.0865 & 1.49 & $120.0812 、 166.0861 、 131.0494 、 107.0497 、 149.0594$ & 37 \\
\hline 65 & 7.09 & Isoscopoletin & $\mathrm{C} 10 \mathrm{H} 8 \mathrm{O} 4$ & 193.0495 & 193.0502 & 3.45 & $\begin{array}{c}193.0502 、 149.0600 、 178.0265 、 133.0290 、 122.0367 、 \\
165.0550 、 162.0500\end{array}$ & Standard \\
\hline 66 & 15.33 & Ritalinic acid & $\mathrm{C} 13 \mathrm{H} 17 \mathrm{~N}$ & 188.1433 & 188.1433 & 0.0154 & 188.1433 & 39 \\
\hline 67 & 5.66 & $\begin{array}{l}\alpha \text {-D-Glucopyranoside, } 2- \\
\text { methoxy-4-methylphenyl }\end{array}$ & $\mathrm{C} 14 \mathrm{H} 20 \mathrm{O} 7$ & 301.1081 & 301.1042 & -1.667 & 301.1042 & Standard \\
\hline \multirow[t]{2}{*}{ NO } & \multirow[t]{2}{*}{$\begin{array}{c}\mathrm{tR} / \mathrm{mi} \\
\mathrm{n}\end{array}$} & \multirow[t]{2}{*}{ alkaloids } & \multirow[t]{2}{*}{$\begin{array}{l}\text { Molecular } \\
\text { formula }\end{array}$} & \multicolumn{2}{|c|}{$\begin{array}{c}{[\mathrm{M}-\mathrm{H}]-\mathrm{OR}[\mathrm{M}+\mathrm{Na}]+\text { ion, }} \\
\mathrm{m} / \mathrm{z}\end{array}$} & Error & \multirow[t]{2}{*}{ fragment ion } & \multirow[t]{2}{*}{ Ref. } \\
\hline & & & & theoretical & measured & & & \\
\hline 68 & 45.25 & Resveratrol & $\mathrm{C} 14 \mathrm{H} 12 \mathrm{O} 3$ & 227.0714 & 227.0710 & 3.275 & $\begin{array}{c}227.07101 、 185.06097 、 143.04915 、 130.98273 、 \\
102.95605\end{array}$ & Standard \\
\hline 69 & 36.68 & Oxyresveratrol & $\mathrm{C} 14 \mathrm{H} 12 \mathrm{O} 4$ & 243.0662 & 243.0662 & -0.36 & 243.06612、201.05516、159.95518、 & Standard \\
\hline
\end{tabular}




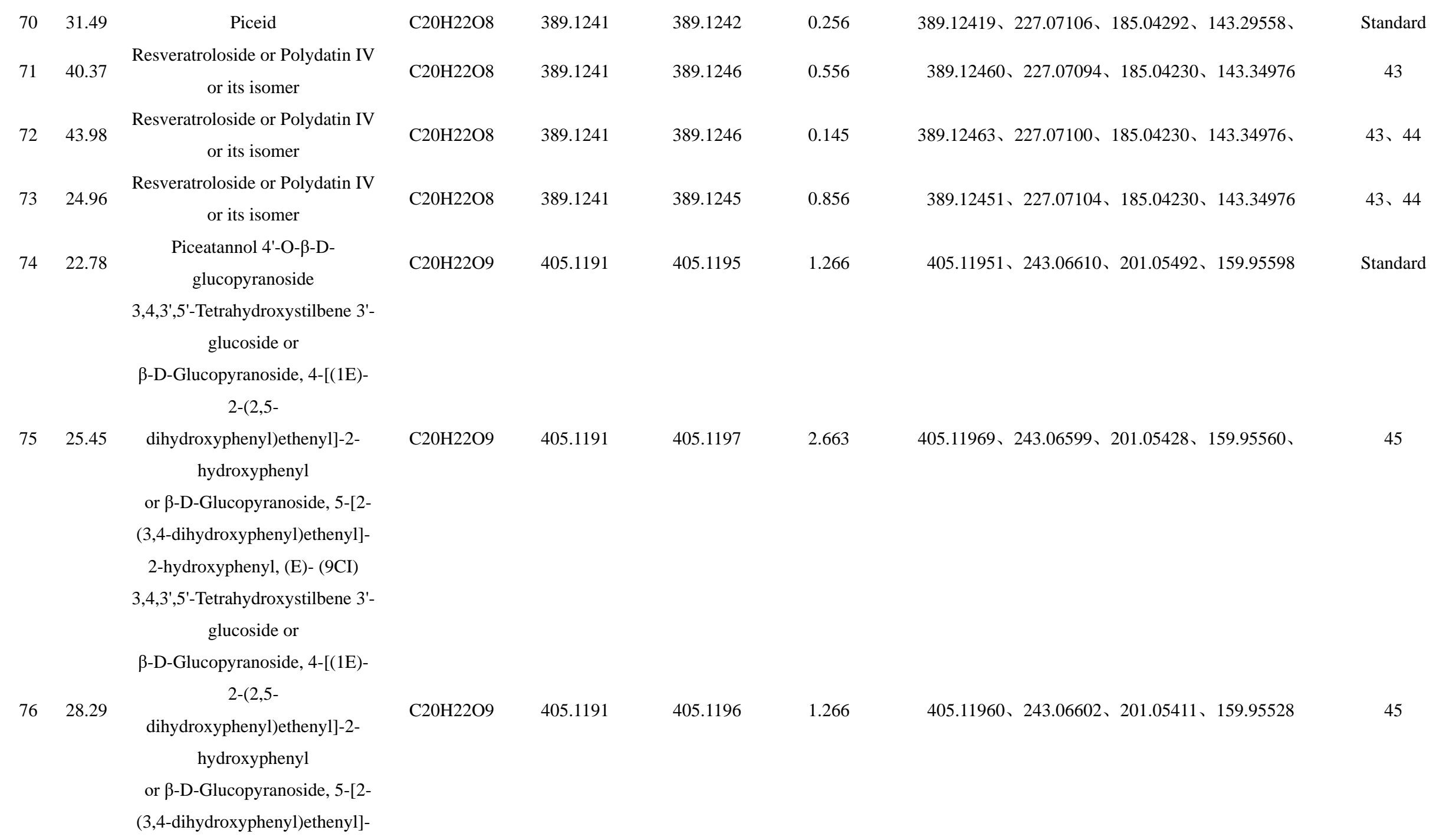


2-hydroxyphenyl, (E)- (9CI)

3,4,3',5'-Tetrahydroxystilbene 3'-

$$
\text { glucoside or }
$$

$\beta$-D-Glucopyranoside, 4-[(1E)-

$$
2-(2,5-
$$

or $\beta$-D-Glucopyranoside, 5-[2-

\section{(3,4-dihydroxyphenyl)ethenyl]-}

2-hydroxyphenyl, (E)- (9CI)

$7848.81 \quad$ Resveratrol 4'-methyl ether

3,3',5-Stilbenetriol, 4'-methoxy-,

$$
\text { (E)- (8CI) }
$$

resveratrol-4,3'-di-O- $\beta$-D-

glucopyranoside or its isomer

Piceatannol 3,4'-di- $\beta$-D-

glucopyranoside

Mulberroside A

Mulberroside E

\section{$\mathrm{C} 15 \mathrm{H} 14 \mathrm{O} 3$}

241.0870

3.661

C15H14O4

257.0819

257.0827

2.748

$\mathrm{C} 26 \mathrm{H} 32 \mathrm{O} 13 \quad 551.1770$

551.1715

$\mathrm{C} 26 \mathrm{H} 32 \mathrm{O} 14$

567.1719

567.1717

$-1.231$

$\mathrm{C} 26 \mathrm{H} 32 \mathrm{O} 14$

567.1719

567.1721

3.661

$\mathrm{C} 26 \mathrm{H} 32 \mathrm{O} 13$

597.1834

597.1834

(E)-Resveratrol 3,5-O- $\beta$ diglucoside

C26H32O13 597.1834

597.1837

$-0.245$

$\beta$-D-Glucopyranoside, 3-

hydroxy-5-[(1E)-2-(4-

hydroxyphenyl)ethenyl]phenyl 2-O- $\beta$-D-glucopyranosyl-

$\mathrm{C} 26 \mathrm{H} 32 \mathrm{O} 13$

597.1834
$-0.859$

$597.18362 、 435.13316 、 389.12463 、 227.07104$
46 


\begin{tabular}{|c|c|c|c|c|c|c|c|c|}
\hline 86 & 32.25 & $\begin{array}{l}\text { resveratrol-4,3'-di-O- } \beta \text {-D- } \\
\text { glucopyranoside }\end{array}$ & $\mathrm{C} 26 \mathrm{H} 32 \mathrm{O} 13$ & 551.1770 & 551.1771 & 0.859 & 551.1771、209.1436 & Standard \\
\hline 87 & 40.77 & desoxyrhaponticin & $\mathrm{C} 21 \mathrm{H} 24 \mathrm{O} 8$ & 427.2663 & 427.2609 & -3.55 & $427.2609 、 223.0467$ & Standard \\
\hline 88 & 4.33 & L-Pyroglutamic acid methyl este & C6H9NO3 & 166.0475 & 166.04746 & 0.256 & 166.04746 & Standard \\
\hline 89 & 27.41 & $\begin{array}{c}\beta \text {-D-Glucopyranoside,2- } \\
\text { methoxy-4-(2-propen-1- } \\
\text { yl)phenyl-6-O- } \beta \text {-D- } \\
\text { glucopyranosyl }\end{array}$ & $\mathrm{C} 22 \mathrm{H} 32 \mathrm{O} 12$ & 489.1967 & 489.19665 & -0.145 & 489.19665、 & Standard \\
\hline 90 & 20.33 & $\begin{array}{l}\beta \text {-D-Glucopyranoside, 2,6- } \\
\text { dimethoxy-4-(2-propen-1- } \\
\text { yl)phenyl 6-O-b-D- } \\
\text { glucopyranosyl }\end{array}$ & $\mathrm{C} 23 \mathrm{H} 34 \mathrm{O} 13$ & 541.1892 & 541.1891 & -0.114 & 541.1891、 & Standard \\
\hline 91 & 1.03 & Arginine & C6H14N4O2 & 173.1043 & 173.1034 & 0.527 & $173.10339 、 131.08144 、 86.05969 、 73.02814 、 59.01230$ & 51 \\
\hline 92 & 2.36 & $\begin{array}{c}\text { 4-Oxo-4H-pyran-2,6- } \\
\text { dicarboxylic acid }\end{array}$ & $\mathrm{C} 7 \mathrm{H} 4 \mathrm{O} 6$ & 182.9935 & 182.9926 & 1.012 & 182.99257、139.00259、95.01260、67.01754 & 52 \\
\hline 93 & 3.25 & Citric Acid & $\mathrm{C} 7 \mathrm{H} 8 \mathrm{O} 7$ & 203.0197 & 203.0196 & -0.526 & $191.02145 、 146.93759 、 102.94756 、 85.02814$ & 53 \\
\hline 94 & 2.69 & Quinic acid & $\mathrm{C} 7 \mathrm{H} 12 \mathrm{O} 6$ & 191.0561 & 191.0555 & -0.361 & $191.05547 、 131.03400 、 87.00739$ & 54 \\
\hline 95 & 2.41 & Pectinose & $\mathrm{C} 5 \mathrm{H} 10 \mathrm{O} 5$ & 195.0503 & 195.0504 & -1.554 & $195.05038 、 177.03941 、 159.02879 、 141.01820$ & 55 \\
\hline 96 & 16.89 & 2-(4-Hydroxybenzyl)malic acid & $\mathrm{C} 11 \mathrm{H} 12 \mathrm{O} 6$ & 239.0561 & 239.0558 & -2.175 & $239.05531 、 195.06573 、 150.06341 、$ & 56 \\
\hline
\end{tabular}

